\title{
Community pharmacist's professional adaptation amid Covid-19 emergency: a national survey on Italian pharmacists
}

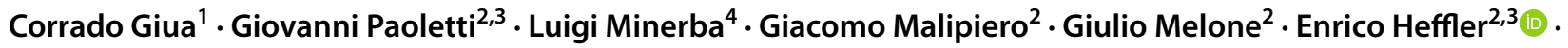 \\ Assunta Pistone ${ }^{1} \cdot$ Enrico Keber $^{1} \cdot$ on behalf of SIFAC Group of Clinical Community Pharmacists (SGCP)
}

Received: 4 September 2020 / Accepted: 31 December 2020 / Published online: 15 January 2021

(c) The Author(s), under exclusive licence to Springer Nature Switzerland AG part of Springer Nature 2021

\begin{abstract}
Background Italy has been the first non-Asian country affected by Coronavirus Disease 19 (COVID-19) pandemic. Community pharmacies are essential services authorized to continue their activity during the emergency. To date, a clear image is lacking of the critical issues Italian community pharmacists had to face and of how they responded in their daily work.. Objective To describe procedures and critical logistical-organizational issues encountered by Italian community pharmacists and to collect the main requests reported by patients to pharmacists. Setting A national survey on Italian community pharmacists. Method A cross-sectional survey using a reasoned questionnaire was sent during the pandemic peak to Italian pharmacies, divided in two groups according to the incidence of COVID-19: "Red Zones" and "non-Red Zones". Main outcome measure Exploring the most frequently adopted measures by the pharmacists. Results 169 community Pharmacists answered the questionnaire. The most frequently adopted measures were the use of gloves, surgical masks and protective barriers at the drug counter. Most implemented services for customers were: booking of prescriptions, delivery of medications and implementation of phone consultations. Overall, the questionnaire highlighted an increase in the number of health-related consultations and requests by customers. In Red Zones, there was a higher use of FFP2 and FFP3 masks by pharmacists, where customers were mainly interested in gaining information about specific classes of medications. Conclusion Community pharmacists adapted to lockdown measures by implementing a number of measures. There was an overall increase in pharmacists' personal protective equipment in Red Zones possibly linked to increased risk perception.
\end{abstract}

Keywords COVID-19 · Education · Pharmacy · Prevention

\section{Impacts on practice}

Corrado Giua and Giovanni Paoletti have contributed equally to this work.

Supplementary Information The online version contains supplementary material available at https://doi.org/10.1007/s1109 6-020-01228-5.

Enrico Heffler

heffler.enrico@gmail.com

Società Italiana Farmacia Clinica (SIFAC), Cagliari, Italy

2 Personalized Medicine, Asthma and Allergy, Humanitas Clinical and Research Center IRCCS, Istituto Clinico Humanitas, Via Alessandro Manzoni 56, 20089 Rozzano, MI, Italy

3 Department of Biomedical Sciences, Humanitas University, Pieve Emanuele, MI, Italy

4 Department of Medical Science and Public Health, University of Cagliari, Cagliari, Italy
- Community pharmacies are among the essential services that should keep working also during a pandemic lockdown.

- Italian community pharmacies were able to rapidly adopt preventive measures for reducing the risk of SARSCoV-2 spreading.

- Community pharmacies became also a reference service for patients seeking for information and education on COVID-19 and related aspects. 


\section{Introduction}

Coronaviruses $(\mathrm{CoV})$ are a large family of respiratory viruses causing mild to severe forms of respiratory diseases [1]. First cases of a new coronavirus pneumonia were reported in December 2019, in the Hubei province of China. In early January 2020, the new coronavirus, tentatively called 2019-nCoV, was isolated and interhuman transmission confirmed [2]. On February 11, 2020, the World Health Organization (WHO) officially defined the new infection as Coronavirus Disease 2019 (COVID19) [3]; right after, the International Committee on Taxonomy of Viruses classified the virus as Acute Respiratory Syndrome Coronavirus 2 (SARS-CoV-2) [4]. After a constant spread all over the world, on 11 March 2020, WHO decreed the state of pandemic for COVID-19 disease [5].

Italy has been the first Western country affected by the Coronavirus pandemic after China [6]. Since the early stages of the pandemic, priority was given to delay and diminish the peak of infection [7], meantime increasing the responsiveness of the Italian national health system. Italy, with the Prime Ministerial Decree of 11 March 2020 [8], was the first Western country to adopt strong containment measures against SARS-CoV-2 infection on the whole national territory. These measures, including social distancing and shutdown of non-essential activities, were necessary to reduce social contacts and viral transmission.

Community pharmacies were among the few essential services authorized to keep their activity ongoing during the emergency and, even during the lockdown, they have been among the most easily accessible healthcare facilities capable of providing advice, information, drugs, and devices to the entire population [9]. Recently, the Italian National Institute for Insurance against Accidents at Work (INAIL) included pharmacies among the activities at high risk of contagion [10]. In an extraordinary circumstance such as a pandemic, disinformation has spread rapidly, generating obvious problems in the healthcare context, where it can delay or prevent effective treatments [11]. A Google search trends' study conducted all over Italy confirmed a growing interest in COVID-19 during the pandemic [12]. Most users consult and evaluate information without having the needed preparation to understand its scientific validity. Since the beginning of the epidemic, the pharmacist had to manage atypical clinical requests and to direct the health information correctly.

One of the main tasks of the pharmacist in this context was to be a point of reference for the territory, providing clear, convenient, and correct answers to questions arising from patients and debunking any fake news. Several guidelines and studies suggested actions pharmacies should undertake during the emergency, both to protect pharmacists and to provide education and support to the customers [13-16]. Even though receiving the same indications, pharmacies have responded with different timing, tools, and policies according to the local situation.

To date, a clear image is lacking of the critical issues Italian pharmacists' community had to face and of how they responded in their daily work.

\section{Aims of the study}

To detect the operating procedures and critical logisticalorganizational issues encountered by Italian community pharmacists during the first months of the emergency period; to collect the main requests, doubts, and changes in needs reported by patients during the emergency.

\section{Ethics approval}

The study has been performed in accordance with the ethical standards laid down in the 1964 Declaration of Helsinki and its later amendments. The study protocol was numbered 03J20 and reviewed and approved by the Ethical Review Board of SIFAC (10th March 2020).

\section{Methods}

\section{Study design}

This is a cross-sectional based on an online survey. A questionnaire (Supplementary electronic material, Annex 1) was developed by the Italian Society of Clinical Pharmacy (SIFAC) with the support of a biostatistician of the University of Cagliari to explore procedures and logistical issues experienced by Italian pharmacists throughout the national territory during the COVID-19 outbreak, as well as to collect health-related queries received from costumers.

The questionnaire consisted of 11 items and was divided into three sections exploring the following areas of interest:

(a) Geolocation and characterization (urban or rural) of the community pharmacy (items 1-3);

(b) Operational methods and organization adopted by the pharmacy during the pandemic (items 4-6). Item 4 investigated the devices used and consisted in 6 fixed options (Surgical mask; DPI; Gloves; Protective visor; Protective barriers at the drug counter; Single use coat and/or shoes cover) plus an open answer to let the pharmacists to describe any other not listed operational methods. Item 5 investigated the implemented sanitization measures (six fixed options: Igenizing gel for customers; Additional use of antiseptics; Continuous disinfection of working tools; Continuous disin- 
fection of working surfaces; Ventilation of pharmacy's building; Sanification through external agency; plus an open answer option). Item 6 investigated new activated services (seven fixed options: Home medicine delivery service through independent pharmacy organization; through volunteers; through specialized delivery companies; Closed doors service; Recipe booking and quick withdrawal of medicines and products; Telephonic consultancy; No added service; plus an open answer option).

(c) Characterization and frequency of customers' queries about health- and medication-related issues, during the study period (items 7-11).

The questionnaire was sent electronically to all SIFAC members working in 230 pharmacies evenly distributed over the Italian territory. Data collection took place between the 8th and 16th of April 2020, which coincides with the period of COVID-19 peak in Italy [17], through a Google Form tool and was subsequently analysed.

\section{Statistical analysis}

for statistical inferential analysis purposes and to better investigate the potential difference in impact that the COVID-19 pandemic had among regions [18], pharmacies were divided in two groups according to COVID-19 incidence: "Red Zones" (Lombardia, Piemonte, Veneto, EmiliaRomagna and Marche), and "non-Red Zones" (all the other Italian regions) as shown in Fig. 1. The regions included in Red Zones were chosen according to the distribution of regional cases, as reported by Livingston et al. [18].

Kolmogorov-Smirnov test was used to evaluate the normality of distribution of continuous variables, and according to its results, the Student t-test or Mann-Whitney test were used for variable comparison. Categorical variables were compared with the Fisher exact test. Continuous variables are presented as mean \pm standard deviation (SD), while categorical variables are presented as percentages. A $p$-value $<0.05$ was considered statistically significant when comparing variables. All the statistical analysis was performed using SPSS 20.0 software (SPSS, Chicago, IL, USA).

\section{Results}

One hundred sixty-nine community pharmacists $(73.5 \%$ of those who received the questionnaire) working in as many community pharmacies adhered to the study and completed the questionnaire.

Table 1 shows the results collected about operational methods and organization at the pharmacy during the

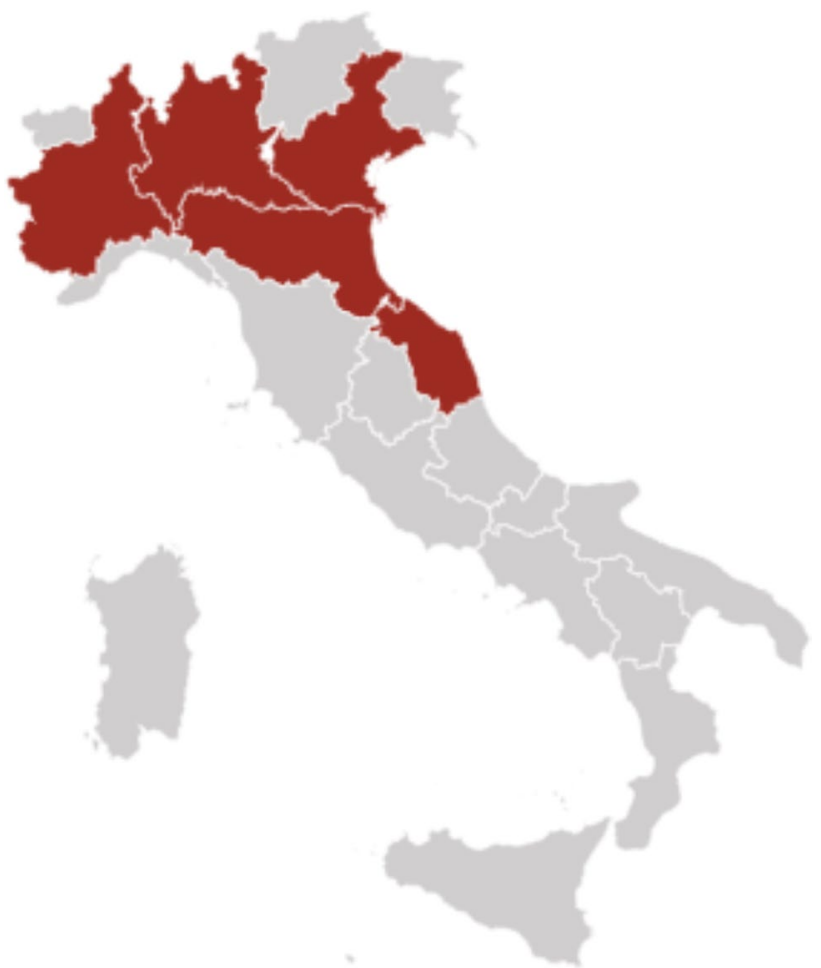

Fig. 1 "Red Zones" (red) and "non-Red Zones" (grey). (Color figure online)

emergency. The mean number of preventive measures adopted by pharmacists was in total $3.43 \pm 1.11$. A statistically non-significant difference was noted in the number of adopted preventive measures between pharmacists in Red Zones and non-Red Zones ( $3.63 \pm 1.10$ vs $3.31 \pm 1.11$, $p=0.07)$. The most frequently adopted measures were the use of gloves $(92.3 \%)$, protective barriers at the drug counter $(86.9 \%)$ and the use of surgical masks $(67.4 \%)$. In Red Zones, it was observed that there was a higher use of Filtering Face Piece 2 and 3 masks (FFP2 and FFP3) compared to non-Red Zones ( $66.2 \%$ vs $49 \%, p=0.03$ ), as well as an increase availability of sanitizing gel for customers $(87.7 \%$ vs $69.2 \%, p=0.006)$. Concerning services that were activated to optimize patients' flow and/or minimize customers' stay in the pharmacies, the mostly implemented ones were: booking of prescriptions and delivery of medications and other products $(61.5 \%)$, implementation of phone consultations (59.2\%) and home-delivery of medicine through volunteer associations (51.5\%); however only the latter was predominant in Red Zones $(61.5 \%$ vs $45.2 \%, p=0.04$ ).

Overall, the questionnaire has highlighted an increase in the answer "above the average" in the number of healthrelated consultations and requests by customers as perceived by the pharmacists (Fig. 2), especially in Red Zones compared to non-Red Zones (84.6\% vs 70.2\%, $p=0.03$ ) (Annex 
Table 1 Operational methods and organization at the pharmacy during the emergency

\begin{tabular}{|c|c|c|c|c|}
\hline Question & Total & Red zones & Non-red zones & $p$-value \\
\hline \multicolumn{5}{|l|}{ With which devices have you been able to accomplish your professional duties? } \\
\hline Surgical mask $(\%)$ & 67.5 & 64.6 & 69.2 & 0.533 \\
\hline FFP2 and FFP3 (\%) & 55.6 & 66.2 & 49.0 & $\mathbf{0 . 0 3}$ \\
\hline Gloves $(\%)$ & 91.7 & 95.4 & 89.4 & 0.17 \\
\hline Face shield $(\%)$ & 27.2 & 26.2 & 27.9 & 0.80 \\
\hline Protective barriers at the counter (e.g. Plexiglas) (\%) & 87.6 & 92.3 & 84.6 & 0.14 \\
\hline Single use coat and/or shoes cover $(\%)$ & 8.9 & 9.2 & 8.7 & 0.90 \\
\hline Protective glasses $(\%)$ & 1.8 & 3.1 & 1.0 & 0.31 \\
\hline $\mathrm{N}^{\circ}$ of preventive measures per pharmacist & $3.43 \pm 1.11$ & $3.63 \pm 1.10$ & $3.31 \pm 1.11$ & 0.07 \\
\hline \multicolumn{5}{|l|}{ Which sanitization measures have been established in your pharmacy? } \\
\hline Hygienizing gel for customers at the pharmacy's entrance (\%) & 76.3 & 87.7 & 69.2 & 0.006 \\
\hline Cleaning adopting additional antiseptics (\%) & 66.9 & 64.6 & 68.3 & 0.623 \\
\hline Continuous disinfection of working tools (computer, cash desk, POS, telephones, etc.) (\%) & 85.8 & 92.3 & 81.7 & 0.055 \\
\hline Continuous disinfection of working surfaces (pharmacy desks, Plexiglas, surfaces, etc.) (\%) & 89.9 & 95.4 & 86.5 & 0.063 \\
\hline Ventilation of the building $(\%)$ & 79.3 & 86.2 & 75.0 & 0.082 \\
\hline Sanification through external agencies (\%) & 40.2 & 32.3 & 45.2 & 0.097 \\
\hline $\mathrm{N}^{\circ}$ of environmental/structural preventive measures & $4.42 \pm 1.33$ & $4.63 \pm 1.12$ & $4.29 \pm 1.43$ & 0.10 \\
\hline \multicolumn{5}{|c|}{ Have new services been activated in order to optimize the flow to the pharmacy and/or minimize the stay in the pharmacy? } \\
\hline Home medicine delivery service through independent pharmacy organization $(\%)$ & 44.4 & 41.5 & 46.2 & 0.557 \\
\hline Home medicine delivery service through volunteer associations (\%) & 51.5 & 61.5 & 45.2 & 0.04 \\
\hline Home medicine delivery service through specialized delivery company, $(\%)$ & 11.2 & 10.8 & 11.5 & 0.88 \\
\hline Closed door service $(\%)$ & 9.5 & 9.2 & 9.6 & 0.93 \\
\hline Prescription booking and quick withdrawal of medications and products (\%) & 61.5 & 63.1 & 60.6 & 0.74 \\
\hline Telephonic consultation implementation (\%) & 59.2 & 55.4 & 61.5 & 0.43 \\
\hline No additional services (\%) & 4.1 & 3.1 & 4.8 & 0.58 \\
\hline No of additional services & $2.44 \pm 1.09$ & $2.46 \pm 1.06$ & $2.43 \pm 1.12$ & 0.868 \\
\hline
\end{tabular}

Bold values indicate statistically significant at $p$ values $<0.05$

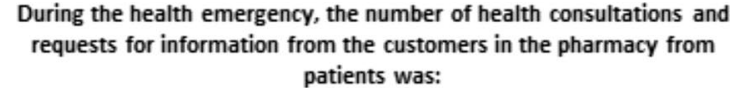
patients was:

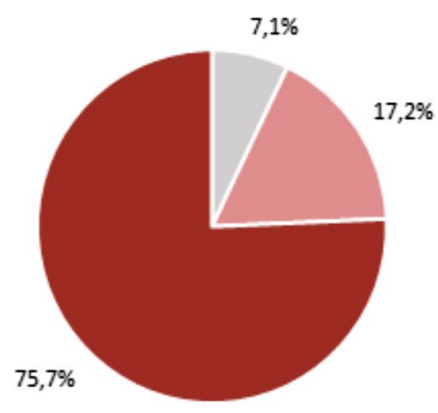

- Below the average | In the average $=$ Above the average
Do you think that the current emergency situation may have increased the confidence perceived by patients towards the professional figure of the community pharmacist?

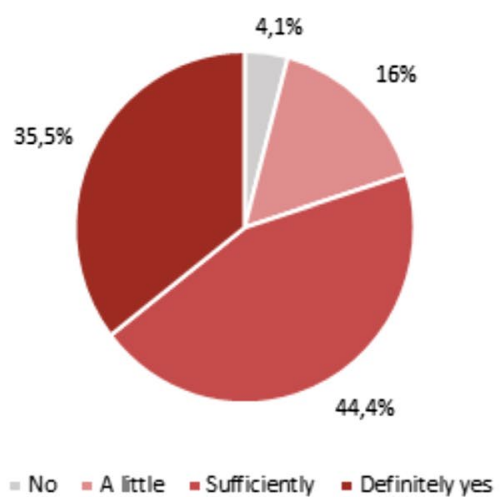

Fig. 2 The role of the community pharmacist and the total, relative increase in information requests from customers in the pharmacy

2 in Supplementary electronic material). Figure 2 also shows the increase in confidence perceived by customers towards the professional figure of the community pharmacist.
Table 2 shows the results collected with regard to the characterization and frequency of requests for healthrelated information from the customers of the pharmacy. A significantly higher percentage of Pharmacists in 
Table 2 Request for information from patients at the pharmacy during the emergency

\begin{tabular}{|c|c|c|c|c|}
\hline Question & Total & Red Zones & Non-Red Zones & P-value \\
\hline \multicolumn{5}{|c|}{$\begin{array}{l}\text { Based on your daily experience during the emergency phase, } \\
\text { how often is the request for the following types of consultations } \\
\text { presented? }\end{array}$} \\
\hline \multicolumn{5}{|c|}{ Informative question } \\
\hline Never $(\%)$ & 1.2 & 0 & 1.9 & N.A \\
\hline Sometimes, $(\%)$ & 18.3 & 15.4 & 20.2 & 0.43 \\
\hline Usually (\%) & 43.8 & 46.2 & 42.3 & 0.62 \\
\hline Very often $(\%)$ & 36.7 & 38.5 & 35.6 & 0.70 \\
\hline \multicolumn{5}{|c|}{ Clarification question } \\
\hline Never $(\%)$ & 0 & 0 & 0 & N.A \\
\hline Sometimes (\%) & 17.8 & 16.9 & 18.3 & 0.82 \\
\hline Usually (\%) & 48.5 & 50.8 & 47.1 & 0.64 \\
\hline Very often $(\%)$ & 33.7 & 32.3 & 34.6 & 0.76 \\
\hline \multicolumn{5}{|c|}{ Motivational support request } \\
\hline Never $(\%)$ & 6.5 & 1.5 & 9.6 & 0.04 \\
\hline Sometimes (\%) & 44.4 & 49.2 & 41.3 & 0.31 \\
\hline Usually (\%) & 29.6 & 32.3 & 27.9 & 0.54 \\
\hline Very often $(\%)$ & 19.5 & 16.9 & 21.2 & 0.50 \\
\hline \multicolumn{5}{|c|}{ Need of reassurance } \\
\hline Never $(\%)$ & 1.2 & 0 & 1.9 & N.A \\
\hline Sometimes (\%) & 29.6 & 35.4 & 26 & 0.19 \\
\hline Usually (\%) & 37.9 & 44.6 & 33.7 & 0.15 \\
\hline Very often (\%) & 31.4 & 20.0 & 38.5 & 0.01 \\
\hline
\end{tabular}

Bold values indicate statistically significant at $p$ values $<0.05$

non-red Zones reported having never been asked for motivational support by the customers compared to those in Red Zones (9.6\% vs 1.5\%, $p=0.04)$. A contrasting pattern however emerged with regard to the need of reassurance, which was instead significantly higher in non-Red Zones compared to Red Zones (38.5\% vs $20 \%, p=0.01$ ).

Figure 3 shows the frequency of requests about medications and the impact of COVID-19 on special conditions such as pregnancy and immunosuppression. In general, the results highlighted a contrasting trend with regard to medication-related information requested by customers. In fact, queries regarding non-steroidal anti-inflammatory drugs (NSAIDs) and hypertensive medications were more frequent in non-Red Zones (answer "very often": $27.9 \%$ vs. $13.8 \%, p=0.03 ; 13.5 \%$ vs. $3.1 \%, p=0.02$ ), while information related to symptomatic medications for respiratory tract infections, such as antitussives and antipyretics, were more frequent in Red Zones (answer: "very often": $50.8 \%$ vs. $30.8 \%, p=0.009$ ). Analysis of queries concerning preventive measures highlights that in Red Zones there was a trend towards a higher number of requests for information related to blood oxygen meters
(72.3\% vs $57.7 \%, p=0.05$ ) (Figure S1, Supplementary electronic material).

\section{Discussion}

In Italy, the Government declared the state of Emergency in January 2020 and promulgated a number of consecutive decrees mandating social distancing [9]. Working activities were regulated based on INAIL classification of workrelated risk of becoming infected [10]. Even though the risk for pharmacists was deemed high, as later confirmed by data from Cabas et al. [19], pharmacists' activities were considered essential and were not interrupted during the pandemic, even though not specifically regulated by health authorities. To the authors' best knowledge, only the Federation of the Orders of Italian Pharmacists (FOFI) provided pharmacists with specific educational material to better cope against the COVID-19 spread [20].

A considerable number of fake or contradictory news were available online or diffused word-of mouth fueling misbeliefs, myths and negations during the pandemic [21, 22]. It is thus essential that pharmacists are prepared and reliable and collaborate to unload the burden of misinformation and misbeliefs in customers, for example by providing up to date information on the safety of NSAIDs and hypertensive medications [23], as these drugs have been the most frequently subjected to fake news in relation to their possible (and unconfirmed) action favoring SARS-CoV-2 infection [21]. The results of this survey show that, during the lock-down, Pharmacists, being at the crossroad between the National Health Service and patients/caregivers, were actively involved in providing health-related information to the general population about different topics: 3 on 4 pharmacists delivered an above the average number of consultations to customers during the first wave of the pandemic (Fig. 2).

According to Al-Quteimat et al. [24] home delivery of drugs and devices and on line consultation offer the possibility to support patients. During the lockdown period, several services were activated by health-care providers to ensure a continuous supply of medications to customers, in particular home-delivery services, by exploiting resting military workforces or volunteers. Moreover, to decrease the need for physical visits to primary care whilst ensuring access is not affected, the Health Minister developed a "fast track" for prescription filling by the general practitioner and dispensing from the pharmacy [25]. The physician could tele-transmit an electronic prescription code to his/her patient, who then turns it to the pharmacy by phone or mail to get his/her prescription prepared and then dispensed without spending unnecessary time waiting at 

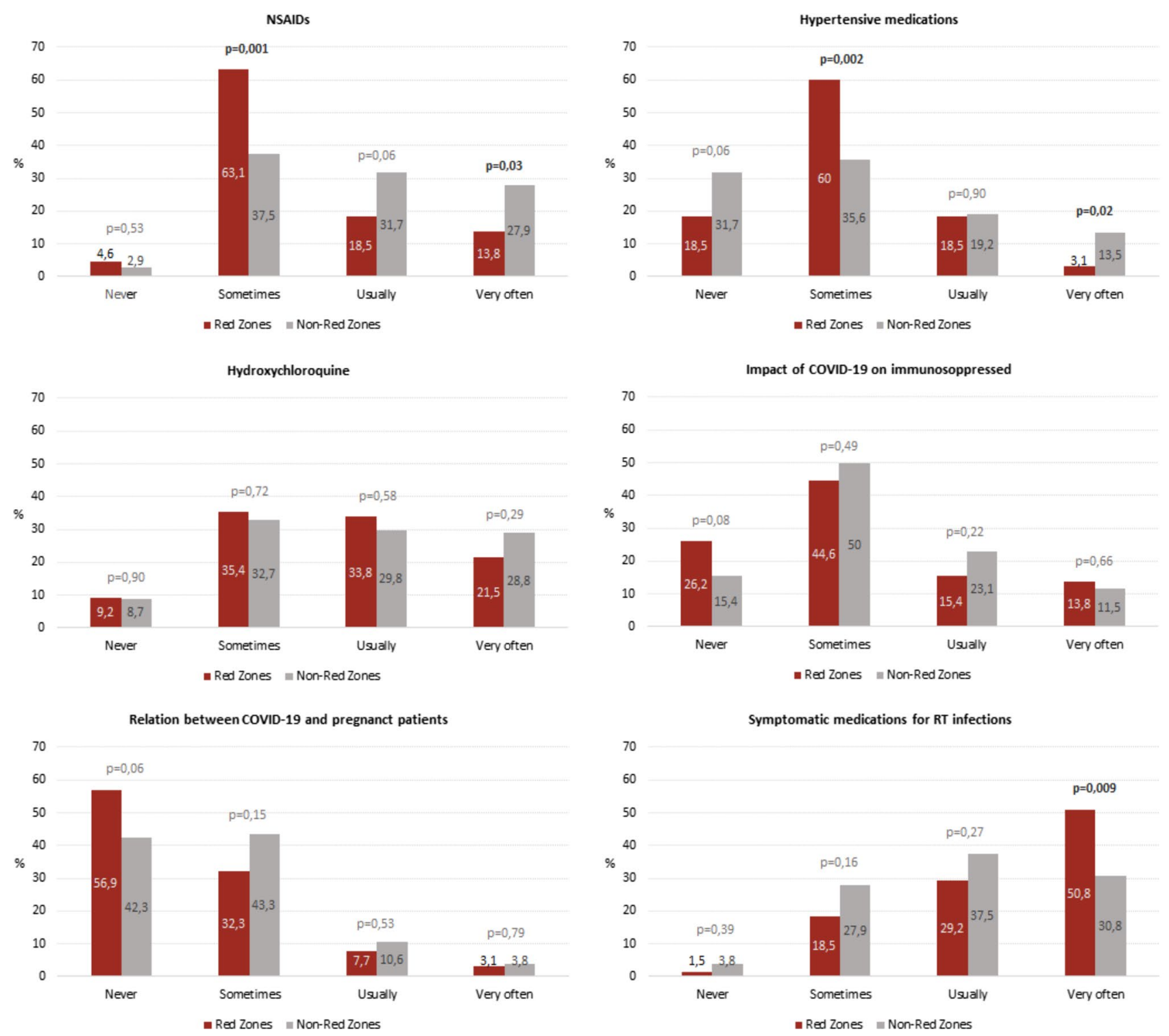

Fig. 3 Frequency of queries for medication-related information, and medical condition-related information from the customers

the pharmacy. About $60 \%$ of general practitioner adopted the new modality.

Several other cross-sectional studies or surveys have been performed so far in order to investigate the various nuances of pharmacists' engagement within the COVID19 pandemic. The major aspects that were investigated consisted in access to COVID-19-related information [26], preparedness [26, 27], knowledge [28, 29] and changes in perception of the role of the pharmacist [28]. This study therefore contributes to the panoramic view necessary to better tailor the role of the community pharmacist in the fight against COVID-19.

Peculiarly in Italy, the national territory was involved by the pandemics in a north to south gradient [18]. Thus comparative analysis between areas of higher CODIV-19 prevalence (Red zones), grossly corresponding to north Italy, and areas of lower COVID-19 prevalence (non-Red zones), corresponding to central-southern Italy was feasible. The results outline a trend concerning the mean total number of preventive measures adopted by pharmacies, which was slightly higher in Red Zones. This might be explained by the increased perception of risk by community pharmacists working in regions with a higher COVID-19 prevalence, a risk that was still present, even though at a lower rate, in the rest of the country, justifying the minimal difference between the obtained values. This explanation is further supported by taking into account results obtained when considering the relative higher use of FFP2 and FFP3 masks in Red Zones compared to non-Red Zones; this is particularly relevant as, unfortunately, not all the other health care workers (i.e.: 
doctors, nurses...), in some local areas of the Country, had adequate access to personal protective equipment leading also to high rate of infection and death. Sanitizing gels for customers at the entrance of the pharmacy was available in a higher number of pharmacies in Red Zones compared to non-Red Zones, denoting further a generalized feel of threat. Of all the services that were implemented, the one that mostly differed between the two zones was "home medicine delivery service through volunteer associations". It was predominant in Red Zones where, for the aforementioned reasons, people, especially elders, refrained from leaving the house even for important reasons such as medicine retrieval.

A rather interesting pattern emerged from our results concerned customers' queries about classes of medications. Customers in non-Red Zones requested information about two drug classes in particular, NSAIDs and hypertensive medications, relatively more often than customers in Red Zones. Instead, in Red Zones, customers' concerns were mainly oriented to symptomatic medications for respiratory tract infections, such as antitussives. This data are only apparently contradictory. Since angiotensin converting enzymes inhibitors (ACE-Is) and NSAIDs had been initially linked to an increased risk of COVID-19 [30-32], people were presumably more interested in obtaining information to reduce the risk of COVID-19 where the disease had not yet epidemically spread whereas in Red regions customers' queries shifted to symptoms-related concerns. This data can be visualized by means of Google Trends, which highlights a peak in searches for ACE-Is and NSAIDs in the initial phase of the COVID-19 pandemic in Italy [33].

One of the main limitation of this study is that the questionnaire we used has not been formally validated to explore the multidimensional issues connected to the unfolding of a widespread health emergency such as COVID-19 pandemic was. The reason for this was intrinsic in the need of collecting timely information from community pharmacies during the unexpected COVID-19 pandemic related outbreak.

Following the rapid spread of COVID-19 around the globe, multiple national and international societies have provided recommendations to be implemented by pharmacies and pharmacists in order to fight the viral spread [34-36]. A systematic review [37] of these guidelines has highlighted inconsistencies and dishomogeneities, probably mirroring different epidemiological settings and prevision models, lack of certainty about main routes of transmission and political beliefs (for example, about the possibility of reaching herd immunity).

\section{Conclusion}

In conclusion, this study showed that Italian community pharmacists adapted to lockdown measures by implementing a number of measures: in particular, there was an overall increase in pharmacists' personal protective equipment in Red Zones possibly linked to increased risk perception. Moreover, the role of community pharmacists was particularly important during the COVID-19 outbreak as their scientific expertise was required by customers for receiving reliable information on several health-related and drugrelated aspects, therefore debunking any fake news.

Overall, this study has in fact highlighted how the professional figure of the community pharmacist has emerged on the pandemic stage, establishing itself as a valuable landmark for customers.

Funding This research did not receive any specific grant from funding agencies in the public, commercial, or not-for-profit sectors.

Conflicts of interest Dr. Heffler reports personal fees from AstraZeneca, Sanofi, GSK, Novartis, Circassia, Nestlè Purina, Boheringer Ingheleim, and Valeas, outside the submitted work. All the other Authors declare not to have conflict of interest.

\section{References}

1. Chen N, Zhou M, Dong X, Qu J, Gong F, Han Y, et al. Epidemiological and clinical characteristics of 99 cases of 2019 novel coronavirus pneumonia in Wuhan, China: a descriptive study. Lancet. 2020;395(10223):507-13.

2. Lu R, Zhao X, Li J, Niu P, Yang B, Wu H, et al. Genomic characterisation and epidemiology of 2019 novel coronavirus: implications for virus origins and receptor binding. Lancet. 2020;395(10224):565-74.

3. WHO. Novel Coronavirus (2019-nCoV) Situation Report-22. [Internet] [cited 2020 May 8]. https://www.who.int/docs/defaultsource/coronaviruse/situation-reports/20200211-sitrep-22-ncov. pdf?sfvrsn=fb6d49b1_2.

4. Coronaviridae Study Group of the International Committee on Taxonomy of Viruses. The species Severe acute respiratory syndrome-related coronavirus: classifying 2019-nCoV and naming it SARS-CoV-2. Nat Microbiol. 2020;4:536-44.

5. WHO Director-General's opening remarks at the media briefing on COVID-19 - 11 March 2020 [Internet]. [cited 2020 May 8]. https://www.who.int/dg/speeches/detail/who-director-general-sopening-remarks-at-the-media-briefing-on-covid-19---11-march -2020 .

6. Johns Hopkins Coronavirus Resource Center. COVID-19 Map [Internet] [cited 2020 Apr 2] https://coronavirus.jhu.edu/map. html.

7. Fong MW, Gao H, Wong JY, Xiao J, Shiu EYC, Ryu S, et al. Nonpharmaceutical measures for pandemic influenza in nonhealthcare settings-social distancing measures. Emerg Infect Dis. 2020;5:976-84.

8. DECRETO DEL PRESIDENTE DEL CONSIGLIO DEI MINISTRI 11 marzo 2020 [Internet]. [cited $2020 \mathrm{Apr}$ 7]. https://www. gazzettaufficiale.it/eli/id/2020/03/22/20A01807/sg. 
9. Sebastiani G, Massa M, Riboli E. Covid-19 epidemic in Italy: evolution, projections and impact of government measures. Eur J Epidemiol. 2020;4:341-5.

10. Istituto Nazionale per l'Assicurazione contro gli Infortuni sul Lavoro (INAIL). Documento tecnico sulla possibile rimodulazione delle misure di contenimento del contagio da SARS-CoV-2 nei luoghi di lavoro e strategie di prevenzione [Internet]. 2020. https ://www.inail.it/cs/internet/docs/alg-pubbl-rimodulazione-conte nimento-covid19-sicurezza-lavoro.pdf.

11. Wang Y, McKee M, Torbica A, Stuckler D. Systematic literature review on the spread of health-related misinformation on social media. Soc Sci Med. 2019;240:112552.

12. Rovetta A, Bhagavathula AS. COVID-19-related web search behaviors and infodemic attitudes in Italy: infodemiological study. JMIR Public Health Surveill. 2020;6(2):e19374.

13. Ung COL. Community pharmacist in public health emergencies: Quick to action against the coronavirus 2019-nCoV outbreak. Res Soc Adm Pharm. 2020;4:583-6.

14. International Pharmaceutical Federation (FIP). Coronavirus SARS-CoV-2 / COVID-19 pandemic: Information and Guidelines for Pharmacists and the Pharmacy Workforce [Internet]. 2020 [cited 2020 Apr 2]. https://www.fip.org/files/content/priority-areas /coronavirus/Coronavirus-guidance-update-ENGLISH.pdf.

15. Bukhari N, Rasheed H, Nayyer B, Babar ZU. Pharmacists at the frontline beating the COVID-19 pandemic. J Pharm Policy Pract. 2020;13:8.

16. Li H, Zheng S, Liu F, Liu W, Zhao R. Fighting against COVID-19: Innovative strategies for clinical pharmacists. Research in Social and Administrative Pharmacy. Elsevier Inc.; 2020.

17. Civil Protection Department of the Italian Government: http:// opendatadpc.maps.arcgis.com/apps/opsdashboard/index.html\#/ b0c68bce2cce478eaac82fe38d4138b1. Accessed 03 Sep 2020.

18. Livingston E, Bucher K. Coronavirus Disease 2019 (COVID-19) in Italy. JAMA. 2020 Mar 17.

19. Cabas P, Di Bella S, Giuffrè M, Rizzo M, Trombetta C, Luzzati $\mathrm{R}$, et al. Community pharmacists' exposure to COVID-19. Res Social Adm Pharm. 2020;S1551-7411(20):30547-57.

20. Scarpa N, Sghedoni D, Valetto MR. Il nuovo coronavirus SARSCoV-2 - edizione per i farmacisti. Quesiti Clin. 2020;11(3).

21. Orso D, Federici N, Copetti R, Vetrugno L, Bove T. Infodemic and the spread of fake news in the COVID-19-era. Eur J Emerg Med. 2020. https://doi.org/10.1097/MEJ.0000000000000713.

22. Lancet T. COVID-19: fighting panic with information. Lancet. 2020;395(10224):537.

23. Coronavirus: What do we know about ibuprofen and COVID19? I Euronews [Internet]. [cited 2020]. https://www.euronews. com/2020/03/18/coronavirus-fact-check-what-do-we-know-about -ibuprofen-and-covid-19.

24. Al-Quteimat OM MSc, BCOP, Amer AM RPh, MSc. SARSCoV-2 outbreak: How can pharmacists help? Res Social Adm Pharm. 2020; S1551-7411(20):30238-2.

25. Covid-19, ricetta medica via email o con messaggio sul telefono [Internet]. [cited 2020 May 10]. www.salute.gov.it/portale/nuovo
coronavirus/dettaglioNotizieNuovoCoronavirus.jsp?lingua=itali ano $\&$ menu $=$ notizie $\& p=$ dalministero $\& i d=4278$.

26. Hoti K, Jakupi A, Hetemi D, Raka D, Hughes J, Desselle S. Provision of community pharmacy services during COVID-19 pandemic: a cross sectional study of community pharmacists' experiences with preventative measures and sources of information. Int J Clin Pharm. 2020; 1-10.

27. Bahlol M, Dewey RS. Pandemic preparedness of community pharmacies for COVID-19. Res Social Adm Pharm. 2020;:S1551-7411(20):30501-5.

28. Meghana A, Aparna Y, Chandra SM, Sanjeev S. Emergency preparedness and response (EP\&R) by pharmacy professionals in India: lessons from the COVID-19 pandemic and the way forward. Res Social Adm Pharm. 2020:S1551-7411(20)30437-X.

29. Abdel Jalil M, Alsous MM, Abu Hammour K, Saleh MM, Mousa R, Hammad EA. Role of pharmacists in COVID-19 disease: a Jordanian perspective. Disaster Med Public Health Prep. 2020;1-7.

30. Coronavirus: What do we know about ibuprofen and COVID-19? । Euronews [Internet]. [cited 2020 May 11]. https://www.euronews. com/2020/03/18/coronavirus-fact-check-what-do-we-know-about -ibuprofen-and-covid-19.

31. European Medicines Agency (EMA). EMA gives advice on the use of non-steroidal anti-inflammatories for COVID-19 [Internet]. [cited 2020 May 11]. www.ema.europa.eu/contact.

32. Capuano A, Scavone C, Racagni G, Scaglione F, Italian Society of Pharmacology. NSAIDs in patients with viral infections, including Covid-19: Victims or perpetrators? Pharmacol Res. 2020;157:104849.

33. Data source: Google Trends. https://www.google.com/trends.

34. Ou HT, Yang YK. Community pharmacists in Taiwan at the frontline against the novel coronavirus pandemic: gatekeepers for the rationing of personal protective equipment. Ann Intern Med. 2020;173(2):149-50.

35. Zheng SQ, Yang L, Zhou PX, Li HB, Liu F, Zhao RS. Recommendations and guidance for providing pharmaceutical care services during COVID-19 pandemic: a China perspective. Res Soc Adm Pharm. 2020;S1551-7411(20):30284-9.

36. Carico RR Jr, Sheppard J, Thomas CB. Community pharmacists and communication in the time of COVID-19: applying the health belief model. Res Soc Adm Pharm. 2020;:S1551-7411(20):30293-X.

37. Hasan SS, Kow CS, Zaidi STR. Social distancing and the use of PPE by community pharmacy personnel: does evidence support these measures? Res Social Adm Pharm. 2020;S1551-7411(20):30490-3.

Publisher's Note Springer Nature remains neutral with regard to jurisdictional claims in published maps and institutional affiliations. 